\title{
Allele Frequencies of the Single Nucleotide Polymorphisms Related to the Body Burden of Heavy Metals in the Korean Population and Their Ethnic Differences
}

\author{
Sang-Yong Eom', Ji-Ae Lim², Yong-Dae Kim', Byung-Sun Choi ${ }^{3}$, Myung Sil Hwang ${ }^{4}$, \\ Jung-Duck Park ${ }^{3}$, Heon Kim ${ }^{1}$ and Ho-Jang Kwon ${ }^{2}$ \\ ${ }^{1}$ Department of Preventive Medicine, College of Medicine, Chungbuk National University, Cheongju, Korea \\ ${ }^{2}$ Department of Preventive Medicine, Dankook University College of Medicine, Cheonan, Korea \\ ${ }^{3}$ Department of Preventive Medicine, Chung-Ang University College of Medicine, Seoul, Korea \\ ${ }^{4}$ Food Risk Analysis Division, National Institute of Food and Drug Safety Evaluation, Cheongju, Korea
}

(Received February 11, 2016; Revised March 13, 2016; Accepted May 19, 2016)

\begin{abstract}
This study was performed to select single nucleotide polymorphisms (SNPs) related to the body burden of heavy metals in Koreans, to provide Korean allele frequencies of selected SNPs, and to assess the difference in allele frequencies with other ethnicities. The candidate-gene approach method and genome-wide association screening were used to select SNPs related to the body burden of heavy metals. Genotyping analysis of the final 192 SNPs selected was performed on 1,483 subjects using the VeraCode Goldengate assay. Allele frequencies differences and genetic differentiations between the Korean population and Chinese (CHB), Japanese (JPT), Caucasian (CEU), and African (YIR) populations were tested by Fisher's exact test and fixation index $\left(F_{\mathrm{ST}}\right)$, respectively. The Korean population was genetically similar to the CHB and JPT populations $\left(F_{\mathrm{ST}}<0.05\right.$, for all SNPs in both populations). However, a significant difference in the allele frequencies between the Korean and CEU and YIR populations were observed in 99 SNPs $(60.7 \%)$ and 120 SNPs (73.6\%), respectively. Ten (6.1\%) and 26 (16.0\%) SNPs had genetic differentiation $\left(F_{\mathrm{ST}}>0.05\right)$ among the Korean-CEU and Korean-YIR comparisons, respectively. The SNP with the largest $F_{\mathrm{ST}}$ value between the Korean and African populations was cystathionine- $\beta$-synthase rs234709 $\left(F_{\mathrm{ST}}\right.$ : KOR-YIR, 0.309; KOR-CEU, 0.064). Our study suggests that interethnic differences exist in SNPs associated with heavy metals of Koreans, and it should be considered in future studies that address ethnic differences in heavy-metal concentrations in the body and genetic susceptibility to the body burden of heavy metals.
\end{abstract}

Key words: Genetic diversity, Single nucleotide polymorphism, Gene frequency, Metals

\section{INTRODUCTION}

It is well known that heavy metals induce adverse health effects in humans, including kidney damage, bone loss, neurological disorders, developmental abnormalities, vascular diseases, and cancer $(1,2)$. Even the general population that does not have occupational exposure is chronically

Correspondence to: Ho-Jang Kwon, Department of Preventive Medicine, Dankook University College of Medicine, 119 Dandaero, Dongnam-gu, Cheonan, Chungnam 31116, Korea E-mail: hojang@dankook.ac.kr

This is an Open-Access article distributed under the terms of the Creative Commons Attribution Non-Commercial License (http:// creativecommons.org/licenses/by-nc/3.0) which permits unrestricted non-commercial use, distribution, and reproduction in any medium, provided the original work is properly cited. exposed to a low concentration of heavy metals because heavy metals are widely distributed in the environment $(1,3)$. Heavy-metal concentration in the body is affected by various factors such as age, sex, smoking, diet, and nutritional status, and the environmental exposure level is a critical factor in determining the body burden of heavy metal $(1,3,4)$. However, heavy metals go through the processes of absorption, distribution, metabolism, and excretion, in which a number of genetic factors are involved directly or indirectly. Therefore, in addition to environmental factors, genetic factors and their interactions may also play important roles in determining heavy-metal concentrations in the body (5). Previous studies reported that single nucleotide polymorphisms (SNPs) of a gene involved in iron metabolism were associated with not only the iron level but also with the lead and cadmium levels $(6,7)$. Furthermore, in a twin study, the 
blood cadmium concentration was more strongly affected by genetics than by environmental factors (8). Therefore, genetic predisposition can play an important role in the body burden of heavy metals.

The blood cadmium and mercury levels in the general Korean population are approximately 2 4 times higher than the levels in the American population (9). Although consuming grains and shellfish was predicted to be a major factor in the heavy-metal high exposure levels of Korean populations (10), the general Korean population's estimated total dietary intake of cadmium was not high compared to that of other nations and was considerably lower (about $30 \%$ ) than the provisional tolerable weekly intake (11). This mismatch between external exposure and internal concentration indicates that there is the possibility that Koreans have a genetic predisposition associated with high absorption, low excretion, and high accumulation rates of heavy metals. Therefore, the goal of this study was to select SNPs related to the body burden of heavy metals, such as lead, mercury, cadmium, and arsenic, provide Korean allele frequencies of selected SNPs, and assess the difference in allele frequencies with other ethnicities.

\section{MATERIALS AND METHODS}

Study subjects. This study was based on a cohort established by the Korean Research Project on Integrated Exposure Assessment to Hazardous Materials for Food Safety (KRIEFS). The characteristics of this KRIEFS cohort and the method used to select the study subjects were described in detail in previous studies (12). Out of the 2,118 adults who enrolled in a KRIEFS cohort, 1,558 consented to participating in the genetic study. Among them, 71 subjects were excluded for the following reasons: incomplete data on heavy-metal exposure $(n=48)$ and insufficient blood sample $(n=23)$. Ultimately, 1,487 subjects were selected as study subjects. This study was approved by the Institutional Review Board of Dankook University Hospital, Republic of Korea (IRB No. 2013-03-008), and informed consent was obtained from all individual participants included in the study.

Selection of SNPs-related body burden of heavy metals in the Korean population and genotyping analysis. The candidate-gene approach method and genome-wide association screening using an exome chip were performed to select SNPs related to the body burden of heavy metals in the Korean population.

Candidate-gene approach: The genes involved in absorption, distribution, metabolism, and excretion of heavy metals were selected as candidate genes through a literature review, and databases search, such as Catalog of Published GWAS (13) and HuGE Navigator (14). SNPs located in the transcription regulatory region (promoter region or start codon) and the coding region (splice site, exon, or stop codon) of the selected candidate genes were selected as candidate SNPs using the Functional Element SNPs Database II (15). We searched the International HapMap Project database (HapMap Data Rel 27, population CHB and JPT/Rsquare cutoff 0.9 , minor allele frequency cutoff 0.05 ) for the haplotype tagging SNP of each candidate gene and selected the candidate SNPs from this source.

Genome-wide association screening: After randomly selecting 500 people from the study subjects, genome-wide association screening was conducted using a Human Exome chipv1.2 (Illumina, San Diego, USA) in which 244,770 SNPs could be simultaneously analyzed. There were 783 SNPs not in Hardy-Weinberg equilibrium (HWE) $(p<0.001)$, and 309 SNPs had call rates of less than $95 \%$. The average call rate of all samples was greater than $99.9 \%$, with a minimum value of $99.4 \%$. As a result of conducting a blind replication test on 20 randomly selected samples, the error rate of all samples was less than $0.05 \%$, and the average concordance rate was $99.96 \%$. For the SNPs located on autosomal chromosomes that satisfied the call rate $(>95 \%)$ and were in HWE $(p>0.001)$, the association with the marker of heavy-metal body burden (blood lead, blood cadmium, blood mercury, urinary cadmium and total arsenic) was evaluated by multiple regression analysis using the program PLINK, and 81 significant SNPs $\left(p<1.0 \times 10^{-4}\right)$ were selected.

Genotyping analysis: Ultimately, 192 SNPs were selected based on the candidate-gene approach method and genome-wide association screening. Genotyping analysis was performed on the selected 192 SNPs using the VeraCode Goldengate assay (Illumina, San Diego, CA, USA). An analysis was performed on 1,483 subjects who passed the DNA quality control (QC). The average call rate of the samples was $99.41 \%$, and the average call rate of the SNPs was $99.38 \%$. From 15 of the 192 total SNPs that were not in HWE, six SNPs with call rates less than $95 \%$ and two samples with call rates less than $95 \%$ were excluded from the final analysis. As a result of conducting a blind replication test on 19 randomly selected samples, high reproducibility was confirmed with an average concordance rate of $99.5 \%$.

SNP frequencies in other ethnic populations. The frequencies of the selected SNPs in other ethnic populations were investigated using the Database of Single Nucleotide Polymorphisms (dbSNP build 142) and International HapMap DB (HapMap Data Rel \#27 Phases I, II, and III). In this study, the gene frequencies in the Korean population were compared to those in four ethnic populations: Han Chinese individuals from Beijing, China (CHB), Japanese individuals from Tokyo, Japan (JTP), Caucasian individuals from Utah, USA of Northern and Western European ancestry from the Centre de'Etude du Polymorphism Humaincollection (CEU), and African Yoruba individuals in Ibadan, Nigeria (YRI). 
Statistical analysis. HWE and allele frequency, as determined by the program PLINK, were used to analyze the data for 192 SNPs in the Korean individuals in this study. Based on the minor allele in the Korean population, the allele frequencies in each ethnic group were calculated. For the 163 SNPs that passed SNP QC, the difference in SNP frequencies between the Korean populations and other ethnic groups was compared using Fisher's exact test. For each of the SNPs, we used Bonferroni correction for multiple tests and set the statistical significance threshold to $p$ value $<3.1 \times 10^{-4}\left(0.05 / 163 \quad \mathrm{SNPs}=3.1 \times 10^{-4}\right)$. Genetic differentiation among four ethnicities was measured by the Fixation index $\left(F_{\mathrm{ST}}\right)$, which describes the degree of population differentiation based on genetic polymorphisms (16). $F_{\text {ST }}$ among a pairwise comparison between different ethnic groups was schematized with a Manhattan plot. $F_{\mathrm{ST}}$ at 0.05 to 0.15 was interpreted as moderate genetic differentiation, 0.15 to 0.25 was high genetic differentiation, and above 0.25 was very high genetic differentiation.

\section{RESULTS}

The study was conducted on 1,487 Korean subjects to calculate the allele frequencies of SNPs involved in the body burden of heavy metals, and their demographic characteristics and the level of heavy metals in subjects are presented in Table 1. The mean age of study subjects was $45.5 \pm 14.5$ years, $56.8 \%$ of all subjects was females. The
Table 1. General characteristics of study subjects

\begin{tabular}{|c|c|c|}
\hline & & $N(\%)$ \\
\hline Total subjects & & 1,487 \\
\hline Gender & Males & $643(43.2)$ \\
\hline & Females & $844(56.8)$ \\
\hline Age, mean \pm std. & & $45.5 \pm 14.5$ \\
\hline Age groups & -29 & $255(17.2)$ \\
\hline & $30 \sim 39$ & $266(17.9)$ \\
\hline & $40 \sim 49$ & $341(22.9)$ \\
\hline & $50 \sim 59$ & $334(22.5)$ \\
\hline & $60+$ & $291(19.6)$ \\
\hline Smoking history & Never smokers & $966(65.0)$ \\
\hline & Ex-smokers & $243(16.3)$ \\
\hline & Current smokers & $278(18.7)$ \\
\hline Alcohol use & Non-drinkers & $362(24.3)$ \\
\hline & Drinkers & $1125(75.7)$ \\
\hline Heavy metal level & & \\
\hline Blood lead, unit: & & $2.21(2.17,2.26)$ \\
\hline Blood mercury, uI & & $4.05(3.91,4.19)$ \\
\hline Blood cadmium, $\mathrm{l}$ & $\lg / \mathrm{L}$ & $1.06(1.03,1.09)$ \\
\hline Urinary cadmium & $\mu \mathrm{g} / \mathrm{g}$ creatinine & $1.09(1.05,1.13)$ \\
\hline Urinary total arser & nit: $\mu \mathrm{g} / \mathrm{g}$ creatinine & $102.7(98.03,107.60)$ \\
\hline
\end{tabular}

"Presented as geometric mean and 95\% confidence intervals.

Table 2. Information about the 192 SNPs and allele frequencies tested in this study

\begin{tabular}{|c|c|c|c|c|c|c|c|}
\hline rs ID & Chr. & Gene & Location & Minor allele & MAF & Selection rationale & Related heavy metals \\
\hline rs1948368 & 1 & SIPR1/OLFM3 & Intergenic & $\mathrm{A}$ & 0.003 & Exome chip based & $\mathrm{Cd}$ \\
\hline rs714282 & 1 & GPR177 & Intron & $\mathrm{A}$ & 0.419 & Exome chip based & $\mathrm{Cd}$ \\
\hline rs3736930 & 1 & ATP6V1G3 & Complex & $\mathrm{T}$ & 0.057 & Candidate gene approached & $\mathrm{Cd}$ \\
\hline rs2666839 & 1 & CENPF & Coding & $\mathrm{T}$ & 0.163 & Exome chip based & $\mathrm{Cd}$ \\
\hline rs34545462 & 1 & $S L C 2 A 7$ & Coding & $\mathrm{T}$ & 0.050 & Exome chip based & $\mathrm{Hg}$ \\
\hline rs11265263 & 1 & DUSP23/CRP & Intergenic & $\mathrm{A}$ & 0.170 & Exome chip based & $\mathrm{Cd}$ \\
\hline rs13306731 & 1 & SOAT1 & Coding & $\mathrm{G}$ & 0.380 & Candidate gene approached & $\mathrm{Cd}, \mathrm{Hg}$ \\
\hline rs11118075 & 1 & $R R P 15$ & Coding & $\mathrm{C}$ & 0.070 & Exome chip based & $\mathrm{Hg}$ \\
\hline rs11805194 & 1 & NUP133 & Coding & $\mathrm{C}$ & 0.140 & Exome chip based & $\mathrm{Cd}$ \\
\hline rs2479409 & 1 & BSND/PCSK9 & Intergenic & A & 0.366 & Exome chip based & $\mathrm{Cd}$ \\
\hline rs35351292 & 1 & LAPTM5 & Coding & A & 0.065 & Exome chip based & $\mathrm{Cd}$ \\
\hline rs41268474 & 1 & Clorf68 & Coding & $\mathrm{A}$ & 0.068 & Exome chip based & $\mathrm{Pb}$ \\
\hline rs1284852 & 1 & FLVCR1/VASH2 & Intergenic & $\mathrm{G}$ & 0.446 & Candidate gene approached & $\mathrm{Cd}$ \\
\hline rs58275168 & 1 & $S L C 35 F 3$ & Intron & A & 0.282 & Exome chip based & $\mathrm{Cd}$ \\
\hline rs1476413 & 1 & MTHFR & Intron & $\mathrm{A}$ & 0.176 & Candidate gene approached & As \\
\hline rs4845625 & 1 & IL6R & Intron & $\mathrm{T}$ & 0.443 & Exome chip based & $\mathrm{Pb}$ \\
\hline rs267733 & 1 & ANXA9 & Coding & $\mathrm{G}$ & 0.077 & Exome chip based & $\mathrm{Pb}$ \\
\hline rs2698530 & 2 & PELI1/HSPC159 & Intergenic & $\mathrm{A}$ & 0.350 & Candidate gene approached & $\mathrm{Cd}, \mathrm{Pb}$ \\
\hline rs 1457451 & 2 & LOC729348/LOC100131818 & Intergenic & A & 0.172 & Candidate gene approached & $\mathrm{Cd}$ \\
\hline rs4664325 & 2 & RBMS1 & Intron & G & 0.315 & Exome chip based & $\mathrm{Cd}$ \\
\hline rs 12623234 & 2 & MRPS9/GPR45 & Intergenic & G & 0.476 & Exome chip based & $\mathrm{Cd}$ \\
\hline rs1130609 & 2 & $R R M 2$ & UTR & $\mathrm{G}$ & 0.338 & Candidate gene approached & $\mathrm{Pb}$ \\
\hline rs2165738 & 2 & NCOA1/ITSN2 & Intergenic & $\mathrm{G}$ & 0.387 & Exome chip based & $\mathrm{Hg}$ \\
\hline rs61197218 & 2 & LOC100128572/IQCA1 & Intergenic & $\mathrm{A}$ & 0.271 & Exome chip based & $\mathrm{Hg}$ \\
\hline rs2287059 & 2 & NOL10 & Coding & $\mathrm{T}$ & 0.114 & Exome chip based & $\mathrm{Hg}$ \\
\hline
\end{tabular}


Table 2. Continued

\begin{tabular}{|c|c|c|c|c|c|c|c|}
\hline rs ID & Chr. & Gene & Location & Minor allele & MAF & Selection rationale & Related heavy metals \\
\hline rs 10455 & 2 & $C Y B R D 1$ & UTR & A & 0.331 & Candidate gene approached & $\mathrm{Pb}$ \\
\hline rs3747673 & 3 & TNK2 & Coding & $\mathrm{T}$ & 0.111 & Exome chip based & $\mathrm{Cd}$ \\
\hline rs2293232 & 3 & MUC4 & Coding & $\mathrm{T}$ & 0.219 & Exome chip based & $\mathrm{Cd}$ \\
\hline rs3817672 & 3 & TFRC & Coding & $\mathrm{A}$ & 0.175 & Candidate gene approached & $\mathrm{Cd}$ \\
\hline rs72953098 & 3 & C3orf30 & UTR & G & 0.067 & Exome chip based & $\mathrm{Hg}$ \\
\hline rs7640978 & 3 & CMTM6 & Intron & $\mathrm{T}$ & 0.057 & Exome chip based & $\mathrm{Cd}$ \\
\hline rs832038 & 3 & GABRR3 & Intron & G & 0.452 & Candidate gene approached & $\mathrm{Pb}, \mathrm{Cd}$ \\
\hline rs6799969 & 3 & $R A D 18 / O X T R$ & Intergenic & $\mathrm{G}$ & 0.358 & Exome chip based & $\mathrm{Cd}$ \\
\hline rs1799852 & 3 & $T F$ & Coding & $\mathrm{T}$ & 0.218 & Candidate gene approached & $\mathrm{Cd}, \mathrm{Pb}$ \\
\hline rs3804141 & 3 & TFRC & Intron & A & 0.212 & Candidate gene approached & $\mathrm{Cd}$ \\
\hline rs2718812 & 3 & TOPBP $1 / T F$ & Intergenic & A & 0.490 & Candidate gene approached & $\mathrm{Cd}$ \\
\hline rs1830084 & 3 & $T F / S R P R B$ & Intergenic & $\mathrm{A}$ & 0.472 & Candidate gene approached & $\mathrm{Cd}, \mathrm{Pb}$ \\
\hline rs75123867 & 3 & CCDC50 & Coding & $\mathrm{T}$ & 0.048 & Exome chip based & $\mathrm{Cd}$ \\
\hline rs3811647 & 3 & $T F$ & Intron & $\mathrm{A}$ & 0.419 & Candidate gene approached & $\mathrm{Cd}$ \\
\hline rs 1561072 & 3 & SOX2OT/ATP11B & Intergenic & $\mathrm{C}$ & 0.180 & Exome chip based & $\mathrm{Hg}$ \\
\hline rs2276790 & 3 & MFI2 & Coding & $\mathrm{T}$ & 0.061 & Candidate gene approached & $\mathrm{Cd}$ \\
\hline rs1049296 & 3 & $T F$ & Coding & $\mathrm{T}$ & 0.266 & Candidate gene approached & $\mathrm{Cd}$ \\
\hline rs34193982 & 4 & NEIL3 & Coding & G & 0.118 & Exome chip based & $\mathrm{Hg}$ \\
\hline rs 74511500 & 4 & FAT1 & Coding & A & 0.091 & Exome chip based & $\mathrm{Hg}$ \\
\hline rs11556167 & 4 & PET112L & Coding & A & 0.059 & Exome chip based & $\mathrm{Cd}$ \\
\hline rs4073 & 4 & RASSF6/IL8 & Intergenic & A & 0.367 & Candidate gene approached & As \\
\hline rs2725264 & 4 & $A B C G 2$ & Intron & $\mathrm{G}$ & 0.219 & Candidate gene approached & $\mathrm{Hg}$ \\
\hline rs17208187 & 5 & TMCO6 & Coding & G & 0.258 & Exome chip based & $\mathrm{Hg}$ \\
\hline rs7579 & 5 & SEPP1 & UTR & A & 0.329 & Candidate gene approached & $\mathrm{Hg}$ \\
\hline rs3822751 & 5 & $G L R X$ & Intron & $\mathrm{C}$ & 0.294 & Candidate gene approached & As \\
\hline rs 2052550 & 5 & $A R S B$ & Intron & G & 0.452 & Candidate gene approached & $\mathrm{Cd}, \mathrm{Pb}$ \\
\hline rs3877899 & 5 & SEPP1 & Coding & - & 0.000 & Candidate gene approached & $\mathrm{Hg}$ \\
\hline rs13188386 & 5 & GHR/LOC100129630 & Intergenic & - & 0.000 & Candidate gene approached & $\mathrm{Cd}, \mathrm{Pb}$ \\
\hline rs2354124 & 5 & MRPL36/LOC728613 & Intergenic & $\mathrm{G}$ & 0.255 & Exome chip based & $\mathrm{Cd}$ \\
\hline rs1130435 & 5 & FABP6 & Complex & $\mathrm{T}$ & 0.456 & Exome chip based & $\mathrm{Cd}$ \\
\hline rs3749779 & 5 & $S L C 25 A 2$ & Coding & G & 0.095 & Exome chip based & $\mathrm{Hg}$ \\
\hline rs1801394 & 5 & MTRR & Complex & G & 0.283 & Candidate gene approached & $\mathrm{Cd}$ \\
\hline rs3765467 & 6 & GLPIR & Coding & $\mathrm{T}$ & 0.252 & Exome chip based & $\mathrm{Hg}$ \\
\hline rs2301227 & 6 & $H L A-D P A 1$ & Intron & $\mathrm{C}$ & 0.073 & Exome chip based & $\mathrm{Cd}, \mathrm{Hg}$ \\
\hline rs3129953 & 6 & C6orf10/BTNL2 & Intergenic & $\mathrm{T}$ & 0.083 & Exome chip based & $\mathrm{Cd}$ \\
\hline rs76100089 & 6 & LOC729792 & Coding & $\mathrm{T}$ & 0.203 & Exome chip based & $\mathrm{Hg}$ \\
\hline rs1800629 & 6 & $T N F / L T A$ & Intergenic & A & 0.068 & Candidate gene approached & $\mathrm{Cd}$ \\
\hline rs17270561 & 6 & SLC17A1 & Intron & A & 0.145 & Candidate gene approached & $\mathrm{Pb}, \mathrm{Cd}$ \\
\hline rs13194984 & 6 & $B T N 1 A 1 / B T N 2 A 1$ & Intergenic & $\mathrm{T}$ & 0.007 & Candidate gene approached & $\mathrm{Cd}, \mathrm{Pb}$ \\
\hline rs17342717 & 6 & SLC17A1 & Intron & $\mathrm{T}$ & 0.008 & Candidate gene approached & $\mathrm{Cd}, \mathrm{Pb}$ \\
\hline rs2071593 & 6 & ATP6V1G2 & UTR & $\mathrm{T}$ & 0.084 & Candidate gene approached & $\mathrm{Hg}$ \\
\hline rs3957356 & 6 & GSTA1/GSTA5 & Intergenic & $\mathrm{T}$ & 0.156 & Candidate gene approached & $\mathrm{Hg}$ \\
\hline rs932316 & 6 & $S C G N / L R R C 16 A$ & Intergenic & $\mathrm{C}$ & 0.136 & Candidate gene approached & $\mathrm{Cd}, \mathrm{Pb}$ \\
\hline rs12216125 & 6 & HIST1HIA/TRIM38 & Intergenic & $\mathrm{T}$ & 0.122 & Candidate gene approached & $\mathrm{Cd}, \mathrm{Hg}$ \\
\hline rs1799945 & 6 & $H F E$ & Complex & G & 0.048 & Candidate gene approached & $\mathrm{Cd}, \mathrm{Pb}$ \\
\hline rs9357283 & 6 & DNAH8 & Coding & A & 0.314 & Candidate gene approached & $\mathrm{Cd}$ \\
\hline rs4516970 & 6 & WTAP/SOD2 & Intergenic & - & 0.000 & Candidate gene approached & $\mathrm{Cd}, \mathrm{Pb}$ \\
\hline rs2274089 & 6 & $L R R C 16 A$ & Intron & A & 0.031 & Candidate gene approached & $\mathrm{Cd}, \mathrm{Pb}$ \\
\hline rs1183201 & 6 & SLC17A1 & Intron & A & 0.143 & Candidate gene approached & $\mathrm{Hg}$ \\
\hline rs17883901 & 6 & GCLC/KLHL31 & Intergenic & $\mathrm{T}$ & 0.115 & Candidate gene approached & $\mathrm{Hg}$ \\
\hline rs2858881 & 6 & $H L A-D Q B 1 / H L A-D Q A 2$ & Intergenic & G & 0.048 & Exome chip based & $\mathrm{Hg}$ \\
\hline rs3736781 & 6 & $B T N 1 A 1$ & Coding & G & 0.314 & Candidate gene approached & $\mathrm{Hg}$ \\
\hline rs2142672 & 6 & $M Y L I P / G M P R$ & Intergenic & $\mathrm{C}$ & 0.264 & Exome chip based & $\mathrm{Pb}$ \\
\hline rs972275 & 6 & LOC728666/RSPO3 & Intergenic & G & 0.458 & Candidate gene approached & $\mathrm{Cd}, \mathrm{Pb}$ \\
\hline rs35868297 & 7 & GALNTL5 & Coding & $\mathrm{C}$ & 0.196 & Exome chip based & $\mathrm{Cd}$ \\
\hline rs194524 & 7 & STEAP2 & Complex & A & 0.213 & Candidate gene approached & $\mathrm{Pb}$ \\
\hline
\end{tabular}


Table 2. Continued

\begin{tabular}{|c|c|c|c|c|c|c|c|}
\hline rs ID & Chr. & Gene & Location & Minor allele & MAF & Selection rationale & Related heavy metals \\
\hline rs2718021 & 7 & SEPT7/EEPD1 & Intergenic & $\mathrm{T}$ & 0.480 & Exome chip based & $\mathrm{Cd}$ \\
\hline rs13225097 & 7 & LOC100288724/GIMAP4 & Intergenic & $\mathrm{G}$ & 0.188 & Exome chip based & $\mathrm{Cd}$ \\
\hline rs4722266 & 7 & STK31 & Complex & A & 0.260 & Exome chip based & $\mathrm{Pb}$ \\
\hline rs13306698 & 7 & PON1 & Coding & G & 0.086 & Candidate gene approached & $\mathrm{Cd}$ \\
\hline rs29880 & 7 & INHBA/C7orf10 & Intergenic & $\mathrm{G}$ & 0.144 & Candidate gene approached & $\mathrm{Cd}, \mathrm{Pb}$ \\
\hline rs662 & 7 & PON1 & Coding & A & 0.355 & Candidate gene approached & $\mathrm{Pb}$ \\
\hline rs6971925 & 7 & $D G K B$ & Intron & $\mathrm{T}$ & 0.078 & Exome chip based & $\mathrm{Cd}$ \\
\hline rs1106634 & 8 & ATP6V1B2 & Intron & A & 0.211 & Candidate gene approached & $\mathrm{Hg}$ \\
\hline rs8191664 & 8 & NEIL2 & Complex & $\mathrm{T}$ & 0.193 & Exome chip based & $\mathrm{Cd}$ \\
\hline rs11544484 & 8 & TOP1MT & Coding & A & 0.063 & Exome chip based & $\mathrm{Hg}$ \\
\hline rs4732748 & 8 & ESCO2 & Coding & $\mathrm{T}$ & 0.200 & Exome chip based & $\mathrm{Cd}, \mathrm{Hg}$ \\
\hline rs74846385 & 8 & C8orf86 & Coding & $\mathrm{C}$ & 0.106 & Exome chip based & $\mathrm{Cd}$ \\
\hline rs17058207 & 8 & SCARA5 & Coding & $\mathrm{G}$ & 0.320 & Candidate gene approached & $\mathrm{Pb}, \mathrm{Cd}$ \\
\hline rs4872511 & 8 & PPP3CC/SORBS3 & Intergenic & $\mathrm{T}$ & 0.084 & Exome chip based & $\mathrm{Pb}$ \\
\hline rs1800435 & 9 & $A L A D$ & Coding & $\mathrm{C}$ & 0.073 & Candidate gene approached & $\mathrm{Pb}$ \\
\hline rs10818708 & 9 & ORIN1 & Coding & G & 0.099 & Exome chip based & $\mathrm{Cd}$ \\
\hline rs3740393 & 10 & $A S 3 M T$ & Intron & $\mathrm{C}$ & 0.253 & Candidate gene approached & As \\
\hline rs743572 & 10 & CYP17A1 & UTR & $\mathrm{G}$ & 0.496 & Candidate gene approached & As \\
\hline rs1046778 & 10 & $A S 3 M T$ & UTR & $\mathrm{C}$ & 0.385 & Candidate gene approached & As \\
\hline rs10749138 & 10 & $N R A P$ & Coding & $\mathrm{T}$ & 0.419 & Exome chip based & $\mathrm{Hg}$ \\
\hline rs4462262 & 10 & $I P M K / Z W I N T$ & Intergenic & $\mathrm{T}$ & 0.078 & Exome chip based & $\mathrm{Hg}$ \\
\hline rs717620 & 10 & $A B C C 2$ & UTR & $\mathrm{A}$ & 0.222 & Candidate gene approached & $\mathrm{Hg}$ \\
\hline rs11191439 & 10 & $A S 3 M T$ & Coding & $\mathrm{C}$ & 0.014 & Candidate gene approached & As \\
\hline rs10748835 & 10 & $A S 3 M T$ & Intron & $\mathrm{A}$ & 0.491 & Candidate gene approached & As \\
\hline rs156697 & 10 & GSTO2 & Coding & $\mathrm{C}$ & 0.259 & Candidate gene approached & $\mathrm{Cd}$ \\
\hline rs11191453 & 10 & $A S 3 M T$ & Intron & $\mathrm{C}$ & 0.250 & Candidate gene approached & As \\
\hline rs7085104 & 10 & C10orf32/AS3MT & Intergenic & G & 0.435 & Candidate gene approached & As \\
\hline rs2297235 & 10 & GSTO2 & UTR & G & 0.149 & Candidate gene approached & As \\
\hline rs4925 & 10 & GSTO1 & Coding & A & 0.150 & Candidate gene approached & As \\
\hline rs2273697 & 10 & $A B C C 2$ & Coding & A & 0.080 & Candidate gene approached & $\mathrm{Cd}$ \\
\hline rs3740066 & 10 & $A B C C 2$ & Coding & A & 0.245 & Candidate gene approached & $\mathrm{Hg}$ \\
\hline rs3740390 & 10 & $A S 3 M T$ & Intron & A & 0.250 & Candidate gene approached & As \\
\hline rs10891692 & 11 & FAM55A & Coding & $\mathrm{C}$ & 0.382 & Exome chip based & $\mathrm{Cd}$ \\
\hline rs1695 & 11 & GSTP1 & Coding & G & 0.176 & Candidate gene approached & $\mathrm{Cd}, \mathrm{Hg}$ \\
\hline rs4149182 & 11 & SLC22A8 & Intron & $\mathrm{C}$ & 0.316 & Candidate gene approached & $\mathrm{Hg}$ \\
\hline rs11568496 & 11 & $S L C 22 A 8$ & Coding & - & 0.000 & Candidate gene approached & $\mathrm{Hg}$ \\
\hline rs45566039 & 11 & $S L C 22 A 8$ & Coding & - & 0.000 & Candidate gene approached & $\mathrm{Hg}$ \\
\hline rs77030286 & 11 & SNHG1/SNORD28 & Intergenic & - & 0.000 & Candidate gene approached & $\mathrm{Hg}$ \\
\hline rs 10047462 & 11 & KIAA0999 & Intron & G & 0.499 & Candidate gene approached & $\mathrm{Cd}, \mathrm{Pb}$ \\
\hline rs12362209 & 11 & $C C D C 83$ & Coding & G & 0.082 & Exome chip based & $\mathrm{Hg}$ \\
\hline rs236918 & 11 & PCSK7 & Intron & $\mathrm{C}$ & 0.444 & Candidate gene approached & $\mathrm{Cd}, \mathrm{Hg}$ \\
\hline rs4752805 & 11 & PTPRJ & Intron & G & 0.211 & Exome chip based & $\mathrm{Cd}$ \\
\hline rs4149170 & 11 & $S L C 22 A 6$ & UTR & A & 0.278 & Candidate gene approached & $\mathrm{Hg}$ \\
\hline rs1965 & 12 & LOC341378/CKAP4 & Intergenic & G & 0.345 & Candidate gene approached & $\mathrm{Hg}$ \\
\hline rs12229654 & 12 & LOC100131138/CUX2 & Intergenic & G & 0.139 & Exome chip based & $\mathrm{Pb}$ \\
\hline rs11111245 & 12 & $N A V 3 / S Y T 1$ & Intergenic & $\mathrm{C}$ & 0.080 & Exome chip based & $\mathrm{Cd}$ \\
\hline rs2291075 & 12 & SLCO1B1 & Coding & $\mathrm{T}$ & 0.422 & Candidate gene approached & As \\
\hline rs7975232 & 12 & $V D R$ & Intron & A & 0.249 & Candidate gene approached & $\mathrm{Pb}$ \\
\hline rs2464196 & 12 & $H N F 1 A$ & Coding & $\mathrm{C}$ & 0.454 & Candidate gene approached & $\mathrm{Pb}$ \\
\hline rs11066280 & 12 & LOC100287871 & Intron & A & 0.178 & Exome chip based & $\mathrm{Pb}$ \\
\hline rs4304840 & 12 & CLEC4D & Coding & $\mathrm{G}$ & 0.160 & Exome chip based & $\mathrm{Hg}$ \\
\hline rs885389 & 12 & GPR133 & Intron & G & 0.423 & Exome chip based & $\mathrm{Pb}$ \\
\hline rs1564370 & 12 & SLCO1B1 & Intron & $\mathrm{C}$ & 0.259 & Candidate gene approached & As \\
\hline rs10842971 & 12 & $P Z P$ & Coding & $\mathrm{T}$ & 0.063 & Exome chip based & $\mathrm{Hg}$ \\
\hline rs17124715 & 12 & LARP4 & Complex & $\mathrm{C}$ & 0.079 & Exome chip based & $\mathrm{Cd}, \mathrm{Hg}$ \\
\hline rs757343 & 12 & $V D R$ & Intron & A & 0.190 & Candidate gene approached & $\mathrm{Pb}$ \\
\hline
\end{tabular}


Table 2. Continued

\begin{tabular}{|c|c|c|c|c|c|c|c|}
\hline rs ID & Chr. & Gene & Location & Minor allele & MAF & Selection rationale & Related heavy metals \\
\hline rs1800802 & 12 & $E R P 27 / M G P$ & Intergenic & $\mathrm{C}$ & 0.340 & Candidate gene approached & $\mathrm{Pb}$ \\
\hline rs671 & 12 & $A L D H 2$ & Coding & A & 0.158 & Exome chip based & $\mathrm{Pb}$ \\
\hline rs1544410 & 12 & $V D R$ & Intron & A & 0.051 & Candidate gene approached & $\mathrm{Pb}$ \\
\hline rs60683621 & 12 & OR6C70 & Coding & $\mathrm{G}$ & 0.489 & Exome chip based & $\mathrm{Hg}$ \\
\hline rs17278868 & 13 & LATS2/SAP18 & Intergenic & $\mathrm{C}$ & 0.366 & Exome chip based & $\mathrm{Hg}$ \\
\hline rs636437 & 13 & $R F C 3 / N B E A$ & Intergenic & $\mathrm{G}$ & 0.132 & Exome chip based & $\mathrm{Cd}, \mathrm{Hg}$ \\
\hline rs973968 & 14 & FLJ43390/KCNH5 & Intergenic & $\mathrm{G}$ & 0.059 & Candidate gene approached & $\mathrm{Cd}$ \\
\hline rs12879346 & 14 & SLC7A8 & UTR & $\mathrm{T}$ & 0.486 & Candidate gene approached & $\mathrm{Hg}$ \\
\hline rs 12588118 & 14 & SLC7A8 & Intron & $\mathrm{G}$ & 0.096 & Candidate gene approached & $\mathrm{Hg}$ \\
\hline rs34691153 & 14 & SLC7A8 & Coding & - & 0.000 & Candidate gene approached & $\mathrm{Hg}$ \\
\hline rs 1130650 & 14 & $N P$ & Coding & $\mathrm{T}$ & 0.227 & Candidate gene approached & As \\
\hline rs8005905 & 14 & HSP90AA1 & Coding & $\mathrm{T}$ & 0.223 & Candidate gene approached & $\mathrm{Hg}$ \\
\hline rs2234636 & 14 & SLC39A2 & Coding & $\mathrm{C}$ & 0.424 & Candidate gene approached & As \\
\hline rs11549465 & 14 & HIFlA & Coding & $\mathrm{T}$ & 0.053 & Candidate gene approached & $\mathrm{Cd}, \mathrm{Hg}$ \\
\hline rs4984390 & 15 & МСТP2 & Intron & A & 0.318 & Exome chip based & $\mathrm{Hg}$ \\
\hline rs55799438 & 15 & C15orf56 & Coding & G & 0.047 & Exome chip based & $\mathrm{Cd}$ \\
\hline rs13180 & 15 & IREB2 & Coding & $\mathrm{T}$ & 0.465 & Candidate gene approached & $\mathrm{Cd}$ \\
\hline rs11643815 & 16 & MT4 & Coding & A & 0.004 & Candidate gene approached & $\mathrm{Hg}$ \\
\hline rs 28366003 & 16 & $M T 2 A$ & UTR & G & 0.127 & Candidate gene approached & $\mathrm{Cd}$ \\
\hline rs9936741 & 16 & MTIM & UTR & $\mathrm{C}$ & 0.069 & Candidate gene approached & $\mathrm{Hg}$ \\
\hline rs12919719 & 16 & $\mathrm{CDH1}$ & Intron & G & 0.164 & Candidate gene approached & As \\
\hline rs11076161 & 16 & MT1A & Intron & A & 0.292 & Candidate gene approached & $\mathrm{Cd}$ \\
\hline rs4148356 & 16 & $A B C C 1$ & Coding & A & 0.069 & Candidate gene approached & $\mathrm{Pb}$ \\
\hline rs35529209 & 16 & $A B C C 1$ & Coding & - & 0.000 & Candidate gene approached & $\mathrm{Hg}$ \\
\hline rs41395947 & 16 & $A B C C 1$ & Coding & - & 0.000 & Candidate gene approached & $\mathrm{Hg}$ \\
\hline rs33916661 & 16 & $S L C 7 A 5 / C A 5 A$ & Intergenic & G & 0.119 & Candidate gene approached & $\mathrm{Hg}$ \\
\hline rs11075290 & 16 & $A B C C 1$ & Intron & $\mathrm{T}$ & 0.379 & Candidate gene approached & $\mathrm{Hg}$ \\
\hline rs 10636 & 16 & $M T 2 A$ & UTR & $\mathrm{C}$ & 0.266 & Candidate gene approached & $\mathrm{Cd}$ \\
\hline rs3785879 & 17 & LOC100130148/MAPT & Intergenic & A & 0.388 & Candidate gene approached & $\mathrm{Hg}$ \\
\hline rs78388447 & 17 & $E F C A B 3$ & Complex & $\mathrm{G}$ & 0.102 & Exome chip based & $\mathrm{Cd}$ \\
\hline rs242557 & 17 & MAPT/LOC100130148 & Intergenic & G & 0.471 & Exome chip based & $\mathrm{Cd}$ \\
\hline rs542939 & 17 & $A B H D 15$ & Coding & $\mathrm{T}$ & 0.070 & Exome chip based & $\mathrm{Cd}$ \\
\hline rs7216284 & 17 & GGT6 & Coding & A & 0.146 & Candidate gene approached & $\mathrm{Cd}$ \\
\hline rs312893 & 17 & SEPT9 & Intron & $\mathrm{T}$ & 0.163 & Exome chip based & $\mathrm{Cd}$ \\
\hline rs3744807 & 17 & PYCRl & UTR & $\mathrm{T}$ & 0.048 & Exome chip based & $\mathrm{Hg}$ \\
\hline rs 2660917 & 18 & SOCS6/CBLN2 & Intergenic & $\mathrm{C}$ & 0.057 & Candidate gene approached & $\mathrm{Cd}$ \\
\hline rs2276199 & 18 & PSTPIP2 & Coding & $\mathrm{G}$ & 0.439 & Exome chip based & $\mathrm{Pb}$ \\
\hline rs11555891 & 19 & $I R G C$ & Coding & A & 0.132 & Exome chip based & $\mathrm{Hg}$ \\
\hline rs3745262 & 19 & RAVERI & Coding & $\mathrm{C}$ & 0.080 & Exome chip based & $\mathrm{Cd}$ \\
\hline rs10427027 & 19 & $P R D X 2$ & Intron & $\mathrm{C}$ & 0.077 & Candidate gene approached & As \\
\hline rs1644731 & 19 & RDH8 & Coding & A & 0.439 & Exome chip based & $\mathrm{Cd}$ \\
\hline rs4452075 & 19 & ZNF527 & Coding & $\mathrm{G}$ & 0.315 & Exome chip based & $\mathrm{Hg}$ \\
\hline rs1043673 & 19 & $N L R P 2$ & Coding & A & 0.225 & Candidate gene approached & $\mathrm{Cd}$ \\
\hline rs3761144 & 20 & $G S S / M Y H 7 B$ & Intergenic & $\mathrm{C}$ & 0.463 & Candidate gene approached & $\mathrm{Hg}$ \\
\hline rs 1056720 & 20 & $C D C 25 B$ & Complex & $\mathrm{T}$ & 0.331 & Candidate gene approached & $\mathrm{Cd}$ \\
\hline rs2762934 & 20 & CYP24A1 & UTR & A & 0.114 & Exome chip based & $\mathrm{Cd}$ \\
\hline rs4925386 & 20 & LAMA5 & Intron & $\mathrm{T}$ & 0.225 & Exome chip based & $\mathrm{Cd}$ \\
\hline rs62200482 & 20 & FERMT1 & Coding & A & 0.071 & Exome chip based & $\mathrm{Cd}$ \\
\hline rs6126559 & 20 & VSTM2L & Intron & A & 0.472 & Exome chip based & $\mathrm{Pb}$ \\
\hline rs4920037 & 21 & $C B S$ & Intron & A & 0.026 & Candidate gene approached & As \\
\hline rs234709 & 21 & $C B S$ & Intron & $\mathrm{T}$ & 0.091 & Candidate gene approached & As \\
\hline rs855791 & 22 & TMPRSS6 & Coding & $\mathrm{C}$ & 0.106 & Candidate gene approached & $\mathrm{Cd}, \mathrm{Pb}$ \\
\hline rs987710 & 22 & PRAMEL/VPREBI & Intergenic & G & 0.310 & Candidate gene approached & $\mathrm{Cd}, \mathrm{Pb}$ \\
\hline rs4820268 & 22 & TMPRSS6 & Coding & $\mathrm{G}$ & 0.490 & Candidate gene approached & $\mathrm{Cd}, \mathrm{Pb}$ \\
\hline rs 2430212 & $\mathrm{X}$ & KLHL13 & Intron & $\mathrm{C}$ & 0.299 & Candidate gene approached & $\mathrm{Cd}, \mathrm{Pb}$ \\
\hline
\end{tabular}

Chr.: chromosome, MAF: minor allele frequency, UTR: untranslated region. 
geometric means of blood lead, mercury, cadmium levels in all subjects were $2.21 \mu \mathrm{g} / \mathrm{dL}, 4.05 \mu \mathrm{g} / \mathrm{L}$ and $1.06 \mu \mathrm{g} / \mathrm{L}$, respectively. The geometric mean concentrations of cadmium and total arsenic in urine were $1.06,102.7 \mu \mathrm{g} / \mathrm{g}$ creatinine, respectively.

Table 2 shows the annotation information, minor allele frequency and selection rationale for the 192 selected SNPs.
For the 163 SNPs that passed SNP QC, the allele frequency of minor (variant) alleles in the Korean population and the allele frequencies in CHB, JPT, CEU, and YIR were compared by pairwise comparison; the results are presented in Supplemental Table 1. Six SNPs (3.7\%) showed a statistically significant difference in allele frequency between the Korean and CHB populations, and eight SNPs (4.9\%) dif-
(A)

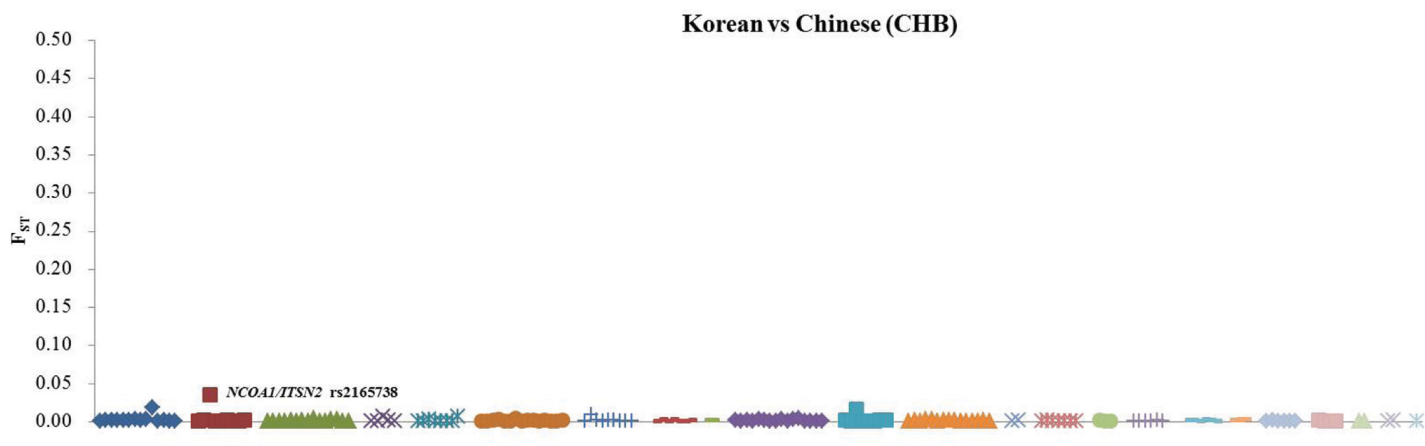

(B)

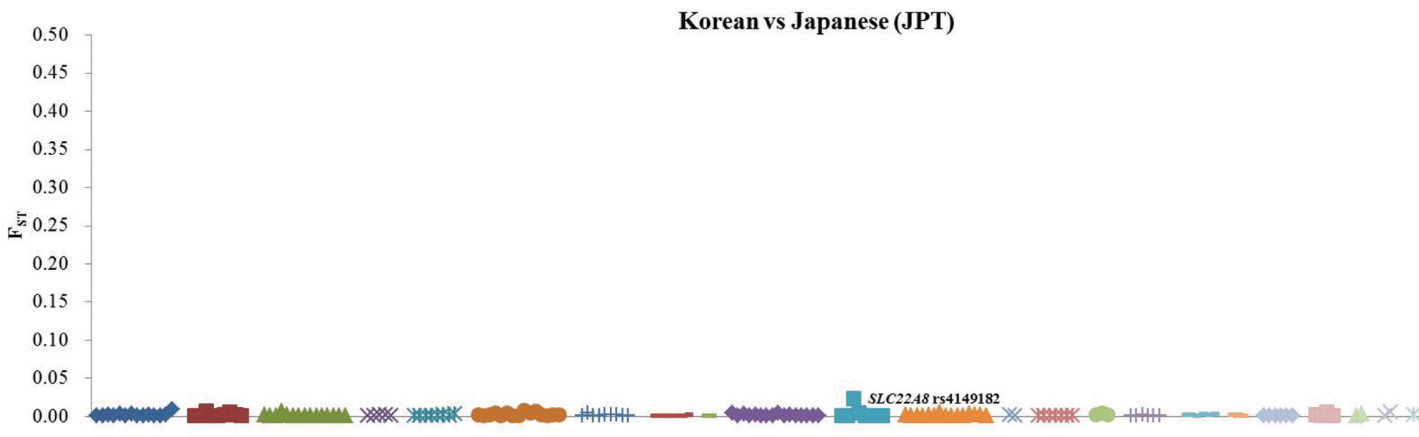

(C)

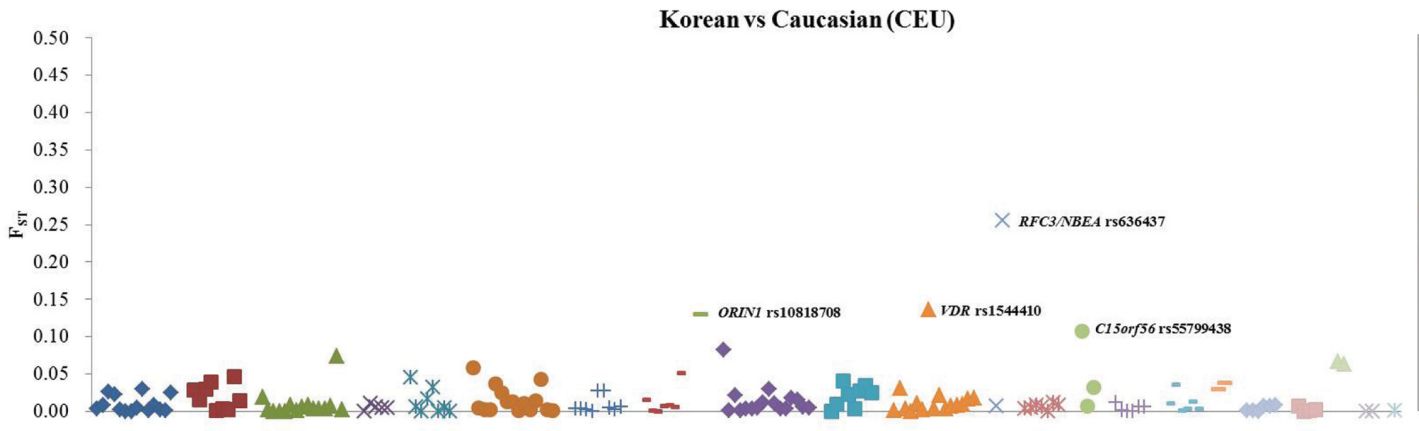

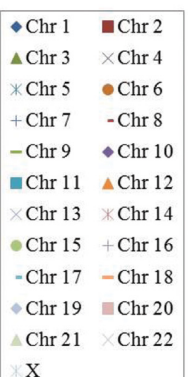

(D)

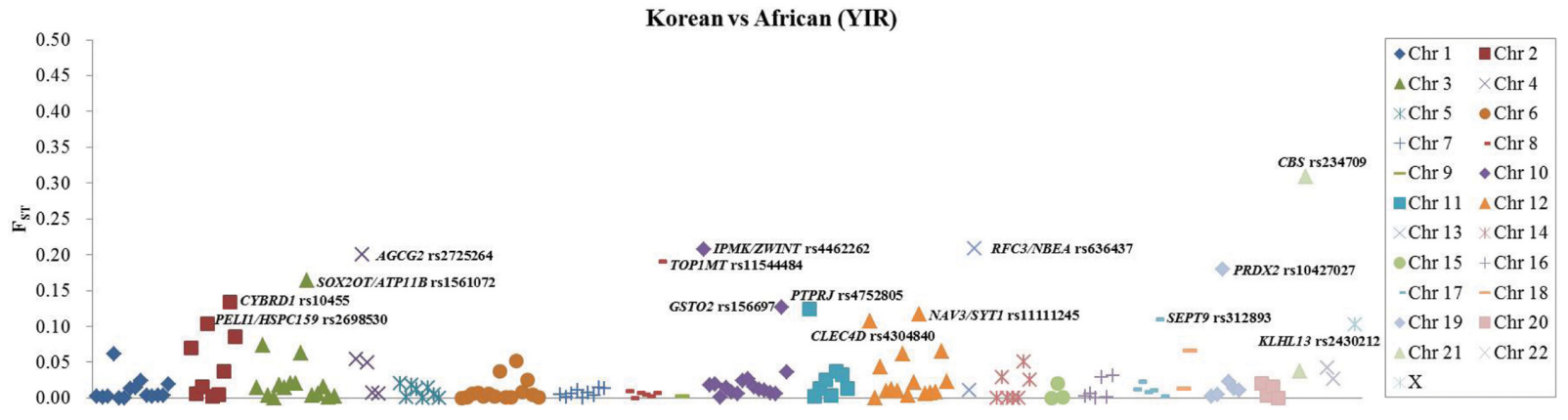

Fig. 1. Genetic differentiation between Korean and other ethnic populations. A: Korean versus Chinese (CHB). B: Korean versus Japanese (JPT). C: Korean versus Caucasian (CEU). D: Korean versus African (YIR).

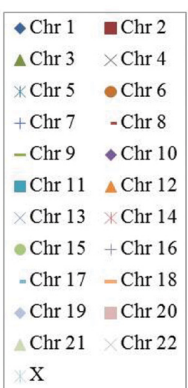
$\begin{array}{ll}\star \mathrm{Chr} 1 & \square \mathrm{Chr} 2 \\ \triangle \mathrm{Chr} 3 & \times \mathrm{Chr} 4 \\ * \mathrm{Chr} 5 & \bullet \mathrm{Chr} 6 \\ +\mathrm{Chr} 7 & -\mathrm{Chr} 8 \\ -\mathrm{Chr} 9 & \bullet \mathrm{Chr} 10 \\ -\mathrm{Chr} 11 & \Delta \mathrm{Chr} 12 \\ \times \mathrm{Chr} 13 & \times \mathrm{Chr} 14 \\ -\mathrm{Chr} 15 & +\mathrm{Chr} 16 \\ -\mathrm{Chr} 17 & -\mathrm{Chr} 18 \\ \star \mathrm{Chr} 19 & -\mathrm{Chr} 20 \\ \triangle \mathrm{Chr} 21 & \mathrm{Chr} 22 \\ \times \mathrm{X} & \end{array}$ 
Table 3. Allele frequencies and fixation index $\left(F_{S T}\right)$ among different ethnics for selected 31 SNPs

\begin{tabular}{|c|c|c|c|c|c|c|c|c|c|c|c|c|c|c|c|c|}
\hline \multirow{2}{*}{ SNP ID } & \multirow{2}{*}{ Gene symbol } & \multirow{2}{*}{ Chr. } & \multirow{2}{*}{$\begin{array}{c}\text { Referent/ } \\
\text { variant allele }\end{array}$} & \multicolumn{5}{|c|}{ Variant allele ${ }^{*}$ frequency } & \multicolumn{2}{|c|}{ KOR versus $\mathrm{CHB}$} & \multicolumn{2}{|c|}{ KOR versus JPT } & \multicolumn{2}{|c|}{ KOR versus CEU } & \multicolumn{2}{|c|}{ KOR versus YIR } \\
\hline & & & & KOR & $\mathrm{CHB}$ & JPT & CEU & YIR & $P^{\dagger}$ & $F_{\mathrm{ST}}$ & $P^{\dagger}$ & $F_{\mathrm{ST}}$ & $P^{\dagger}$ & $F_{\mathrm{ST}}$ & $P^{\dagger}$ & $F_{\mathrm{ST}}$ \\
\hline rs2479409 & BSND/PCSK9 & 1 & $\mathrm{~T} / \mathrm{C}$ & 0.37 & 0.32 & 0.39 & 0.65 & 0.79 & 0.115 & 0.0008 & 0.518 & 0.0002 & $8.1 \times 10^{-17}$ & 0.0225 & $5.9 \times 10^{-46}$ & 0.0620 \\
\hline rs10455 & $C Y B R D 1$ & 2 & $\mathrm{G} / \mathrm{A}$ & 0.33 & 0.33 & 0.40 & 0.73 & 0.96 & 1.000 & 0.0001 & 0.047 & 0.0014 & $1.0 \times 10^{-32}$ & 0.0467 & $4.2 \times 10^{-105}$ & 0.1343 \\
\hline rs1130609 & $R R M 2$ & 2 & $\mathrm{~A} / \mathrm{G}$ & 0.34 & 0.37 & 0.35 & 0.74 & 0.98 & 0.573 & 0.0001 & 0.819 & 0.0001 & $1.5 \times 10^{-19}$ & 0.0283 & $1.1 \times 10^{-52}$ & 0.0695 \\
\hline rs2698530 & PELI1/HSPC159 & 2 & $\mathrm{~T} / \mathrm{C}$ & 0.35 & 0.37 & 0.36 & 0.72 & 0.90 & 0.467 & 0.0002 & 0.718 & 0.0001 & $8.7 \times 10^{-28}$ & 0.0388 & $8.9 \times 10^{-79}$ & 0.1035 \\
\hline rs61197218 & LOC100128572/IQCA1 & 2 & $\mathrm{~T} / \mathrm{G}$ & 0.27 & 0.32 & 0.28 & 0.04 & 0.86 & 0.114 & 0.0008 & 0.931 & 0.0000 & $2.1 \times 10^{-15}$ & 0.0148 & $6.8 \times 10^{-56}$ & 0.0860 \\
\hline rs1561072 & SOX2OT/ATP11B & 3 & $\mathrm{G} / \mathrm{A}$ & 0.18 & 0.19 & 0.15 & 0.10 & 0.78 & 0.565 & 0.0003 & 0.368 & 0.0004 & 0.001 & 0.0033 & $1.6 \times 10^{-97}$ & 0.1643 \\
\hline rs1830084 & $T F / S R P R B$ & 3 & $\mathrm{G} / \mathrm{A}$ & 0.47 & 0.58 & 0.50 & 0.65 & 0.91 & $3.9 \times 10^{-4}$ & 0.0039 & 0.447 & 0.0002 & $4.0 \times 10^{-7}$ & 0.0080 & $9.2 \times 10^{-53}$ & 0.0626 \\
\hline rs3817672 & $T F R C$ & 3 & $\mathrm{~T} / \mathrm{C}$ & 0.18 & 0.15 & 0.19 & 0.60 & 0.14 & 0.451 & 0.0002 & 0.651 & 0.0001 & $3.7 \times 10^{-42}$ & 0.0736 & 0.166 & 0.0006 \\
\hline rs7640978 & СМТМ6 & 3 & $\mathrm{~T} / \mathrm{C}$ & 0.06 & 0.05 & 0.05 & 0.10 & 0.31 & 0.785 & 0.0003 & 0.764 & 0.0004 & 0.012 & 0.0026 & $5.4 \times 10^{-36}$ & 0.0736 \\
\hline rs 2725264 & $A B C G 2$ & 4 & $\mathrm{~T} / \mathrm{A}$ & 0.22 & 0.23 & 0.19 & 0.05 & 0.92 & 0.760 & 0.0000 & 0.357 & 0.0002 & $3.6 \times 10^{-11}$ & 0.0109 & $1.7 \times 10^{-132}$ & 0.2004 \\
\hline rs 4073 & RASSF6/IL 8 & 4 & $\mathrm{~T} / \mathrm{C}$ & 0.37 & 0.41 & 0.33 & 0.39 & 0.86 & 0.283 & 0.0004 & 0.297 & & 0.513 & 0.0001 & $7.3 \times 10^{-40}$ & 0.0546 \\
\hline rs2142672 & $M Y L I P / G M P R$ & 6 & $\mathrm{~T} / \mathrm{C}$ & 0.26 & 0.29 & 0.20 & 0.69 & 0.2 & 0.392 & 0.0003 & 0.033 & & $3.7 \times 10^{-38}$ & & 0.835 & .0001 \\
\hline rs2858881 & $H L A-D Q B 1 / H L A-D Q A 2$ & 6 & $\mathrm{~T} / \mathrm{C}$ & 0.05 & 0.05 & 0.12 & 0.01 & 0.24 & 0.767 & 0.0000 & $3.8 \times 10^{-5}$ & & 0.003 & 19 & $4.2 \times 10^{-26}$ & .0516 \\
\hline rs11544484 & TOPIMT & 8 & $\mathrm{G} / \mathrm{A}$ & 0.06 & 0.08 & 0.05 & 0.30 & 0.53 & 0.198 & 0.0009 & 0.773 & 0.0005 & $6.4 \times 10^{-25}$ & 0.0513 & $1.4 \times 10^{-86}$ & 0.1900 \\
\hline rs10818708 & ORIN1 & 9 & $\mathrm{~T} / \mathrm{C}$ & 0.10 & 0.13 & 0.09 & 0.58 & 0.15 & 0.141 & 0.0009 & 0.727 & 0.0002 & $1.1 \times 10^{-61}$ & 0.1300 & 0.015 & 0.0021 \\
\hline rs156697 & GSTO2 & 10 & $\mathrm{C} / \mathrm{A}$ & 0.26 & 0.27 & 0.29 & 0.39 & 0.83 & 0.719 & 0.0001 & 0.307 & 0.0005 & $8.9 \times 10^{-5}$ & 0.0054 & $8.8 \times 10^{-85}$ & 0.1262 \\
\hline rs4462262 & $I P M K / Z W I N T$ & 10 & $\mathrm{~A} / \mathrm{G}$ & 0.08 & 0.05 & 0.03 & 0.42 & 0.61 & 0.190 & 0.0009 & 0.002 & 0.0029 & $7.8 \times 10^{-39}$ & 0.0820 & $6.4 \times 10^{-98}$ & 0.2073 \\
\hline rs4752805 & PTPRJ & 11 & $\mathrm{~A} / \mathrm{G}$ & 0.21 & 0.28 & 0.19 & 0.16 & 0.98 & 0.112 & 0.0008 & 0.791 & 0.0000 & 0.187 & 0.0005 & $8.5 \times 10^{-75}$ & 0.1245 \\
\hline rs11111245 & $N A V 3 / S Y T 1$ & 12 & $\mathrm{G} / \mathrm{T}$ & 0.08 & 0.09 & 0.09 & 0.00 & 0.46 & 0.487 & 0.0000 & 0.612 & 0.0000 & $5.5 \times 10^{-5}$ & 0.0032 & $2.2 \times 10^{-57}$ & 0.1166 \\
\hline rs1544410 & $V D R$ & 12 & $\mathrm{G} / \mathrm{A}$ & 0.05 & 0.04 & 0.11 & 0.44 & 0.27 & 0.383 & 0.0012 & 0.001 & 0.0046 & $5.7 \times 10^{-56}$ & 0.1364 & $4.7 \times 10^{-30}$ & 0.0611 \\
\hline rs2464196 & $H N F 1 A$ & 12 & $\mathrm{~T} / \mathrm{A}$ & 0.45 & 0.52 & 0.38 & 0.70 & 0.90 & 0.031 & 0.0015 & 0.037 & 0.0014 & $6.6 \times 10^{-13}$ & 0.0160 & $8.9 \times 10^{-54}$ & 0.0652 \\
\hline rs4304840 & CLEC4D & 12 & $\mathrm{~A} / \mathrm{G}$ & 0.16 & 0.15 & 0.12 & 0.22 & 0.62 & 0.730 & 0.0000 & 0.072 & 0.0008 & 0.032 & 0.0013 & $1.1 \times 10^{-61}$ & 0.1070 \\
\hline rs636437 & $R F C 3 / N B E A$ & 13 & $\mathrm{C} / \mathrm{T}$ & 0.13 & 0.17 & 0.14 & 0.90 & 0.76 & 0.097 & 0.0010 & 0.608 & 0.0003 & $2.4 \times 10^{-133}$ & 0.2552 & $5.4 \times 10^{-113}$ & 0.2089 \\
\hline rs973968 & FLJ43390/KCNH5 & 14 & $\mathrm{~A} / \mathrm{G}$ & 0.06 & 0.04 & 0.08 & 0.17 & 0.27 & 0.345 & 0.0000 & 0.313 & 0.0000 & $4.2 \times 10^{-8}$ & 0.0119 & $1.3 \times 10^{-26}$ & 0.0508 \\
\hline rs55799438 & C15orf56 & 15 & $\mathrm{G} / \mathrm{A}$ & 0.05 & 0.06 & 0.02 & 0.41 & 0.05 & 0.298 & 0.0008 & 0.062 & 0.0016 & $8.6 \times 10^{-41}$ & 0.1078 & 1.000 & 0.0005 \\
\hline rs312893 & SEPTY & 17 & $\mathrm{~A} / \mathrm{G}$ & 0.16 & 0.21 & 0.19 & 0.00 & 0.63 & 0.062 & 0.0012 & 0.226 & 0.0005 & $1.6 \times 10^{-15}$ & 0.0129 & $1.8 \times 10^{-63}$ & 0.1099 \\
\hline rs2660917 & SOCS6/CBLN2 & 18 & $\mathrm{C} / \mathrm{A}$ & 0.06 & 0.10 & 0.05 & 0.25 & 0.30 & 0.015 & 0.0023 & 0.764 & 0.0003 & $6.5 \times 10^{-19}$ & 0.0376 & $6.4 \times 10^{-33}$ & 0.0667 \\
\hline rs 10427027 & $P R D X 2$ & 19 & $\mathrm{G} / \mathrm{A}$ & 0.08 & 0.07 & 0.08 & 0.10 & 0.56 & 0.553 & 0.0002 & 0.699 & 0.0001 & 0.304 & 0.0005 & $2.6 \times 10^{-85}$ & 0.1802 \\
\hline rs234709 & $C B S$ & 21 & $\mathrm{G} / \mathrm{A}$ & 0.09 & 0.12 & 0.15 & 0.44 & 0.93 & 0.159 & 0.0004 & 0.012 & 0.0020 & $2.8 \times 10^{-30}$ & 0.0637 & $1.3 \times 10^{-135}$ & 0.3093 \\
\hline rs4920037 & $C B S$ & 21 & $\mathrm{C} / \mathrm{T}$ & 0.03 & 0.01 & 0.03 & 0.23 & 0.16 & 0.315 & 0.0004 & 0.666 & 0.0000 & $2.5 \times 10^{-27}$ & 0.0673 & $1.4 \times 10^{-18}$ & 0.0379 \\
\hline rs 2430212 & KLHL13 & $X$ & $\mathrm{~A} / \mathrm{G}$ & 0.30 & 0.36 & 0.39 & 0.24 & 0.91 & 0.279 & 0.0005 & 0.105 & 0.0010 & 0.186 & 0.0007 & $5.3 \times 10^{-72}$ & 0.1028 \\
\hline
\end{tabular}

Chr: chromosome, KOR: Koreans in this study, CHB: Han Chinese in Beijing, China, JTP: Japanese in Tokyo, Japan, CEU: Utah residents with Northern and Western European ancestry from the CEPH collection, YRI: Yoruba in Ibadan, Nigeria.

Variant allele defined as the minor allele in the Korean population. ${ }^{\dagger} P$ value calculated by Fisher's exact test. 
fered between the Korean and JPT populations. However, there was no genetic differentiation among populations because $F_{\mathrm{ST}}$ was less than 0.05 in all SNPs. In the allele frequency comparison between the Korean and CEU populations, significant differences were found in 99 SNPs $(60.7 \%)$, and $F_{\mathrm{ST}}$ was above 0.05 in $10 \mathrm{SNPs}(6.1 \%)$. In comparison between the Korean and YIR populations, 120 SNPs (73.6\%) showed a significant difference in the allele frequency, and $F_{\text {ST }}$ was above 0.05 in 26 SNPs (16.0\%). Therefore, the biggest genetic divergence was observed between the Korean and YIR populations (Fig. 1).

Table 3 shows that 31 SNPs had $F_{\text {ST }}$ above 0.05 at least once in a pairwise comparison between ethnic groups. The SNP with the largest $F_{\mathrm{ST}}$ value between the Korean and CEU populations was rs636437, which is located in the intergenic region between replication factor $C$ subunit 3 $(R F C 3)$ and neurobeachin (NBEA) $\left(F_{\mathrm{ST}}\right.$ : KOR-CEU, 0.255; KOR-YIR, 0.209). The SNP with the largest $F_{\mathrm{ST}}$ value between the Korean and African populations was cystathionine- $\beta$-synthase $(C B S)$ rs234709 ( $F_{\mathrm{ST}}$ : KOR-YIR, 0.309; KOR-CEU, 0.064). The three SNPs had $F_{\mathrm{ST}}$ above 0.05 both in pairwise comparison between the Korean and CEU populations and between the Korean and YIR populations [vitamin D receptor $(V D R)$ rs1544410 $\left(F_{\mathrm{ST}}\right.$ : KOR-CEU, 0.136; KOR-YIR, 0.061), inositol polyphosphate multikinase/ZW10 interacting kinetochore protein (IPMK/ZWINT) rs4462262 ( $F_{\mathrm{ST}}:$ KOR-CEU, 0.082; KOR-YIR, 0.207), and mitochondrial topoisomerase I (TOP1MT) rs $11544484\left(F_{\mathrm{ST}}\right.$ : KOR-CEU, 0.051; KOR-YIR, 0.190)].

\section{DISCUSSION}

Our interethnic comparison study for SNPs related to the body burden of heavy metals revealed that Koreans were genetically very similar to other East Asians, including Chinese and Japanese individuals but considerably different from Caucasian and African individuals. This result was consistent with the ethnic differences in previous studies on SNPs associated with asthma (17), pharmacogenesis (18), and autoimmunity (19), although direct comparison is impossible because the studied SNPs differed. The ethnic differences in SNPs are affected by genetic drift, migration, and natural selection, and verifying these differences will help us better understand the ethnic variations in disease susceptibility and phenotypes as well as complex geneticenvironment interactions (20).

There are several studies reported that the body concentration of heavy metals differs across ethnicity $(21,22)$. The U.S. National Health and Nutrition Examination Survey (NHANES) report shows that the body concentration of heavy metals in Asians was higher than in all other ethnic populations, especially for cadmium, mercury, and arsenic (23). Blood cadmium, mercury and the urinary total arsenic levels in our cohort subjects were about two, five and ten times greater than those in the U.S. population, respectively (23). Until now, it mainly focused on the ethnic differences in environmental factors including dietary habit to explain for this variation. However, our study is the first to verify the ethnic divergence in SNPs that may be related to heavy metal body burden in Koreans.

In this study, $C B S$ rs 234709 showed the highest $F_{\mathrm{ST}}$ value compared between Korean and African individuals $\left(F_{\mathrm{ST}}=\right.$ 0.309 ), and moderate genetic differentiation was observed for both $C B S$ rs234709 and rs4920037 in the comparison between Korean and Caucasian individuals. CBS gene wasselected as a candidate gene because of the association with arsenic metabolism (24). CBS enzyme catalyzes the synthesis of cystathionine from homocysteine. A decrease in CBS activity is associated with the increases in homocysteine concentration in the body. Elevated homocysteine can deplete S-adenosylmethionine which is a methyl donor. Therefore, a modulation in CBS activity by genetic variation might affect methylation capacity in human (24-26). Recently, the evidence for this mechanism has been reported that $C B S$ rs 234709 or rs 4920037 variant allele were associated with an increased in monomethylarsonous acid (a lessmethylated form of arsenic metabolites), while with a decrease in dimethylarsinic acid (a more-methylated form) $(25,26)$. That is, interethnic genetic variations in enzymes involved in arsenic metabolism can affect interethnic differences in methylation capacity, which results in ethnic differences in urine arsenic methylated metabolite compositions $(26,27)$.

In this study, there was a genetic variation between Korean and CEU populations in Transferrin receptor 1 (TFRC) rs3817672 $\left(F_{\mathrm{ST}}=0.0736\right)$, which is involved in iron absorption, and $V D R \operatorname{rs} 1544410\left(F_{\mathrm{ST}}=0.1364\right)$, which is involved in calcium absorption. Because heavy metals such as cadmium and lead are not metabolized in the body, interactions with various essential minerals during absorption and excretion processes can act as an important factor that affects body burden. Deficiency of essential metals such as iron, calcium, and zinc in the body increases absorption of heavy metals such as cadmium and lead (4). Genetic factors associated with iron homeostasis were identified by several GWAS studies (28), and the association between SNPs associated with iron homeostasis and urine cadmium concentration in non-smoking women was reported (7).

Comparison between Korean and CEU populations and between Korean and YIR populations revealed intergenic SNPs, including RFC3/NBEA rs636437 and IPMK/ZWINT rs 4462262, with $F_{\text {ST }}$ values that indicated moderate genetic differentiation. No studies on these two SNPs and body burden of heavy metals have been conducted to date, and the functions of these SNPs have not been identified. Only the association of IPMK/ZWINT rs 4462262 with diabetes retinopathy was reported by a Taiwanese GWAS study (29).

To our knowledge, this is the first report on ethnic differ- 
ences in SNPs associated with the body burden of heavy metals. In this study, we presented the Koreans allele frequencies of SNPs highly associated with the body burden of heavy metals, which were selected using a candidate-gene approach and GWAS in Korean individuals, and compared the allele frequencies with those of Caucasian, African, and other ethnic Asian populations. Compared with other ethnic Asian populations such as Chinese and Japanese people, Korean individuals were not genetically different $\left(F_{\mathrm{ST}}<\right.$ 0.05). However, compared to the Caucasian and African populations, significant differences in allele frequencies were confirmed in more than $60 \%$ of the SNPs analyzed in this study, and high genetic divergence $\left(F_{\mathrm{ST}}>0.05\right)$ was observed in ten (6.1\%) and 26 (16.0\%) SNPs, respectively. Because there have not been many studies on the genetic effects of the body burden of heavy metals to date, ethnic differences in SNPs associated with heavy metals confirmed in this study should be considered in future studies that address ethnic differences in heavy-metal concentrations in the body and genetic susceptibility to the body burden of heavy metals.

\section{ACKNOWLEDGMENTS}

This research was supported by Grant No. 13162MFDS778 from the Ministry of Food and Drug Safety in 2014.

\section{REFERENCES}

1. Jarup, L. (2003) Hazards of heavy metal contamination. $B r$. Med. Bull., 68, 167-82.

2. Tchounwou, P.B., Yedjou, C.G., Patlolla, A.K. and Sutton, D.J. (2012) Heavy metal toxicity and the environment. EXS, 101, 133-164.

3. Christensen, J.M. (1995) Human exposure to toxic metals: factors influencing interpretation of biomonitoring results. Sci. Total Environ., 166, 89-135.

4. Goyer, R.A. (1995) Nutrition and metal toxicity. Am. J. Clin. Nutr., 61, 646S-650S.

5. Nordberg, G.F., Fowler, B.A. and Nordberg, M. (2014). Handbook on the Toxicology of Metals, Academic Press.

6. Kayaalti, Z., Aliyev, V. and Soylemezoglu, T. (2011) The potential effect of metallothionein $2 \mathrm{~A}-5 \mathrm{~A} / \mathrm{G}$ single nucleotide polymorphism on blood cadmium, lead, zinc and copper levels. Toxicol. Appl. Pharmacol., 256, 1-7.

7. Rentschler, G., Kippler, M., Axmon, A., Raqib, R., Ekstrom, E.C., Skerfving, S., Vahter, M. and Broberg, K. (2013) Polymorphisms in iron homeostasis genes and urinary cadmium concentrations among nonsmoking women in Argentina and Bangladesh. Environ. Health Perspect., 121, 467-472.

8. Bjorkman, L., Vahter, M. and Pedersen, N.L. (2000) Both the environment and genes are important for concentrations of cadmium and lead in blood. Environ. Health Perspect., 108, 719-722.

9. Kim, N.S. and Lee, B.K. (2011) National estimates of blood lead, cadmium, and mercury levels in the Korean general adult population. Int. Arch. Occup. Environ. Health, 84, 5363.

10. Kim, N.Y., Ahn, S.J., Ryu, D.Y., Choi, B.S., Kim, H., Yu, I.J. and Park, J.D. (2013) Effect of lifestyles on the blood mercury level in Korean adults. Hum. Exp. Toxicol., 32, 591-599.

11. Lee, H.S., Cho, Y.H., Park, S.O., Kye, S.H., Kim, B.H., Hahm, T.S., Kim, M., Lee, J.O. and Kim, C.I. (2006) Dietary exposure of the Korean population to arsenic, cadmium, lead and mercury. J. Food Compost. Anal., 19, S31-S37.

12. Eom, S.Y., Choi, S.H., Ahn, S.J., Kim, D.K., Kim, D.W., Lim, J.A., Choi, B.S., Shin, H.J., Yun, S.W., Yoon, H.J., Kim, Y.M., Hong, Y.S., Yun, Y.W., Sohn, S.J., Kim, H., Park, K.S., Pyo, H.S., Kim, H., Oh, S.Y., Kim, J., Lee, S.A., Ha, M., Kwon, H.J. and Park, J.D. (2014) Reference levels of blood mercury and association with metabolic syndrome in Korean adults. Int. Arch. Occup. Environ. Health, 87, 501-513.

13. Welter, D., MacArthur, J., Morales, J., Burdett, T., Hall, P., Junkins, H., Klemm, A., Flicek, P., Manolio, T., Hindorff, L. and Parkinson, H. (2014) The NHGRI GWAS Catalog, a curated resource of SNP-trait associations. Nucleic Acids Res., 42, D1001-D1006.

14. Yu, W., Gwinn, M., Clyne, M., Yesupriya, A. and Khoury, M.J. (2008) A navigator for human genome epidemiology. Nat. Genet., 40, 124-125.

15. Kang, H.J., Choi, K.O., Kim, B.D., Kim, S. and Kim, Y.J. (2005) FESD: a Functional element SNPs database in human. Nucleic Acids Res., 33, D518-D522.

16. Wright, S. (1978) Evolution and the Genetics of Populations, Vol. 4: Variability Within and Among Natural Populations, University of Chicago Press, Chicago.

17. Ryu, H.J., Jung, H.Y., Park, J.S., Ryu, G.M., Heo, J.Y., Kim, J.J., Moon, S.M., Kim, H.T., Lee, J.Y., Koh, I., Kim, J.W., Rho, J.K., Han, B.G., Kim, H., Park, C.S., Oh, B., Park, C., Lee, J.K. and Kimm, K. (2006) Gene-based single nucleotide polymorphisms and linkage disequilibrium patterns of 29 asthma candidate genes in the chromosome 5q31-33 region in Koreans. Int. Arch. Allergy Immunol., 139, 209-216.

18. Kim, I.W., Kim, K.I., Chang, H.J., Yeon, B., Bang, S.J., Park, T., Kwon, J.S., Kim, S. and Oh, J.M. (2012) Ethnic variability in the allelic distribution of pharmacogenes between Korean and other populations. Pharmacogenet. Genomics, 22, 829836.

19. Mori, M., Yamada, R., Kobayashi, K., Kawaida, R. and Yamamoto, K. (2005) Ethnic differences in allele frequency of autoimmune-disease-associated SNPs. J. Hum. Genet., 50, 264-266.

20. Collins, F.S., Green, E.D., Guttmacher, A.E. and Guyer, M.S. (2003) A vision for the future of genomics research. Nature, 422, 835-847.

21. Hightower, J.M., O'Hare, A. and Hernandez, G.T. (2006) Blood mercury reporting in NHANES: identifying Asian, Pacific Islander, Native American, and multiracial groups. Environ. Health Perspect., 114, 173-175.

22. McKelvey, W., Gwynn, R.C., Jeffery, N., Kass, D., Thorpe, L.E., Garg, R.K., Palmer, C.D. and Parsons, P.J. (2007) A biomonitoring study of lead, cadmium, and mercury in the blood of New York city adults. Environ. Health Perspect., 115, 1435-1441.

23. CDC (2015) Fourth National Report on Human Exposure to 
Environmental Chemicals: Updated Tables, Centers for Disease Control and Prevention, Atlanta, pp. 156-287.

24. Porter, K.E., Basu, A., Hubbard, A.E., Bates, M.N., Kalman, D., Rey, O., Smith, A., Smith, M.T., Steinmaus, C. and Skibola, C.F. (2010) Association of genetic variation in cystathionine- $\beta$-synthase and arsenic metabolism. Environ. Res., 110, 580-587.

25. Tseng, C.H. (2009) A review on environmental factors regulating arsenic methylation in humans. Toxicol. Appl. Pharmacol., 235, 338-350.

26. Steinmaus, C., Yuan, Y., Kalman, D., Rey, O.A., Skibola, C.F., Dauphine, D., Basu, A., Porter, K.E., Hubbard, A., Bates, M.N., Smith, M.T. and Smith, A.H. (2010) Individual differences in arsenic metabolism and lung cancer in a case-control study in Cordoba, Argentina. Toxicol. Appl. Pharmacol., 247, 138-145.
27. Fu, S., Wu, J., Li, Y., Liu, Y., Gao, Y., Yao, F., Qiu, C., Song, L., Wu, Y., Liao, Y. and Sun, D. (2014) Urinary arsenic metabolism in a Western Chinese population exposed to highdose inorganic arsenic in drinking water: influence of ethnicity and genetic polymorphisms. Toxicol. Appl. Pharmacol., 274, 117-123.

28. Tanaka, T., Roy, C.N., Yao, W., Matteini, A., Semba, R.D., Arking, D., Walston, J.D., Fried, L.P., Singleton, A., Guralnik, J., Abecasis, G.R., Bandinelli, S., Longo, D.L. and Ferrucci, L. (2010) A genome-wide association analysis of serum iron concentrations. Blood, 115, 94-96.

29. Huang, Y.C., Lin, J.M., Lin, H.J., Chen, C.C., Chen, S.Y., Tsai, C.H. and Tsai, F.J. (2011) Genome-wide association study of diabetic retinopathy in a Taiwanese population. Ophthalmology, 118, 642-648. 